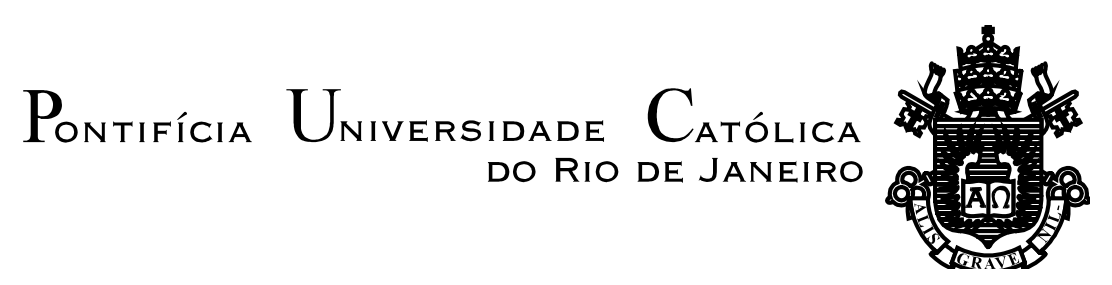

João Carlos de Souza Figueiredo

\title{
Blog educacional como gênero digital: Estudo de caso
}

Dissertação apresentada como requisito parcial para obtenção do título de Mestre pelo Programa de Pós- Graduação em Letras do Departamento de Letras da PUC-Rio.

Orientadora: Profa. Barbara Jane Wilcox Hemais 


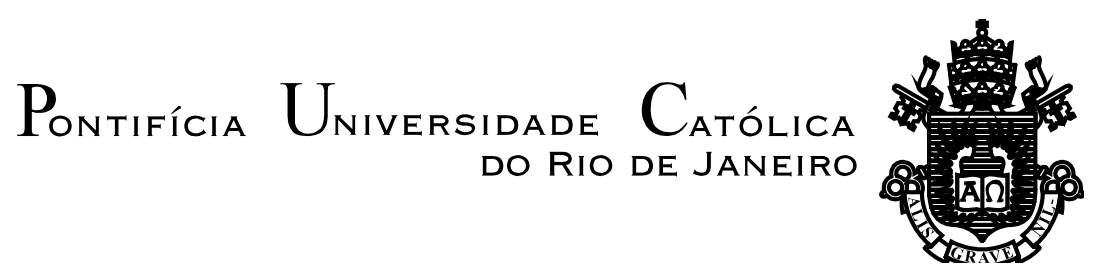

João Carlos de Souza Figueiredo

\section{BLOG EDUCACIONAL COMO GÊNERO DIGITAL: ESTUDO DE CASO}

Dissertação apresentada como requisito parcial para obtenção do grau de Mestre pelo programa de PósGraduação em Letras do Departamento de Letras do Centro de Teologia e Ciências Humanas da PUC-Rio. Aprovada pela Comissão Examinadora abaixo assinada.

Profa. Barbara Jane Wilcox Hemais

Orientadora

Departamento de Letras - PUC-Rio

Profa. Maria Claudia de Freitas

Departamento de Letras - PUC-Rio

Profa. Kátia Modesto Valério

UFF

Profa. Denise Berruezo Portinari

Coordenadora Setorial do Centro de Teologia

e Ciências Humanas - PUC-Rio

Rio de Janeiro, 4 de abril de 2012. 
Todos os direitos reservados. É proibida a reprodução total ou parcial do trabalho sem autorização da universidade, do autor e do orientador.

\section{João Carlos de Souza Figueiredo}

Graduou-se em Letras (Português e Inglês) pela PUC-Rio em 1982. Cursou Especialização em Linguística Aplicada ao Ensino de Língua Inglesa na Universidade do Estado do Rio de Janeiro em 2009. Leciona inglês há 28 anos em cursos de inglês.

Figueiredo, João Carlos de Souza

Blog educacional como gênero digital: estudo de caso / João Carlos de Souza Figueiredo; orientadora: Barbara Jane Wilcox Hemais. - 2012.

93 f.: il.; $30 \mathrm{~cm}$

Dissertação (mestrado)-Pontifícia Universidade Católica do Rio de Janeiro, Departamento de Letras, 2012.

Inclui bibliografia

1. Letras - Teses. 2. Gêneros digitais emergentes. 3. Blog. 4. Processo ensino/aprendizagem. 5. Multimodalidade. I. Hemais, Barbara Jane Wilcox. II. Pontifícia Universidade Católica do Rio de Janeiro. Departamento de Letras. III. Título. 


\section{Agradecimentos}

À Professora Barbara Jane Wilcox Hemais pela competência e dedicação em todos os momentos da preparação de minha dissertação.

Às Professoras Maria Claudia de Freitas, Katia Modesto Valério e Violeta de San Tiago Dantas Barbosa Quental por aceitarem fazer parte da Comissão Examinadora.

À PUC-Rio, pelos auxílios concedidos, sem os quais este trabalho não poderia ter sido realizado.

Aos meus pais, pelo carinho e apoio incondicional em todos os momentos de minha vida.

A todos os meus professores do curso de mestrado da PUC-Rio, por sua ajuda na construção do meu conhecimento acadêmico.

À Chiquinha, secretária de Pós-Graduação do Departamento de Letras, por sua eterna gentileza e boa vontade para comigo.

Aos meus sobrinhos Patrícia e Fernando Figueiredo de Lemos por sua amizade e carinho.

Aos meus amigos do coração, Maria Eugênia Guimarães e Paulo Roberto Borges Maia, pelo seu apoio e carinho.

Ao Dr. Leonardo Lessa, por sua especial ajuda e sem o qual não teria chegado até aqui.

Ao professor Levi Ramos, seus alunos e a Laurel Potter, sem ajuda dos quais esse estudo de caso não teria sido possível. 


\section{Resumo}

Figueiredo, João Carlos de Souza; Hemais, Barbara Jane Wilcox. Blog educacional como gênero digital: Estudo de caso. Rio de Janeiro, 2012. p. 93 Dissertação de Mestrado - Departamento de Letras, Pontifícia Universidade Católica do Rio de Janeiro.

O presente estudo tem por objetivo a análise de um blog educacional mantido por um professor de curso preparatório de um exame de proficiência em língua inglesa. Os aportes teóricos do estudo têm sua base no conceito de gênero discursivo enquanto ação social recorrente e compartilhada por uma comunidade discursiva (Miller, 1994; Swales, 1990) e também a noção de sistema de gêneros (Bazerman, 2005) construído pelo professor e pelos alunos no blog em questão durante o período de nossa observação. $\mathrm{O}$ estudo qualitativo consistiu na definição desse sistema de gêneros e também na investigação de possíveis inclusões no referido blog de gêneros outros que não aqueles comuns em aulas presenciais, por ser o blog um gênero digital e multimediático. Procurou-se também, através da análise de um questionário enviado a nove alunos participantes do blog, verificar a percepção desses alunos quanto ao proveito do uso do blog em questão no que tange ao seu processo de aprendizagem. A análise dos dados mostrou que o sistema de gêneros construído ao longo de nossa observação consistiu basicamente em um sistema bastante similar àquele possivelmente observável em ambiente de sala de aula convencional. Os resultados de nossa análise dos questionários mostraram também que, para a maioria dos alunos, o blog é encarado como proveitoso em termos de aprendizagem conquanto muitos dos alunos não tenham tido uma participação tão efetiva nas atividades propostas pelo professor bloguista. As implicações pedagógicas desta pesquisa remetem à necessidade de se refletir sobre o papel dos novos gêneros digitais no que tange à prática pedagógica dos professores e a contribuição desses gêneros virtuais ao processo ensino e aprendizagem de língua estrangeira nos dias de hoje.

\section{Palavras-chave}

Gêneros digitais emergentes; Blog; Processo ensino/aprendizagem; Multimodalidade 


\section{Abstract}

Figueiredo, João Carlos de Souza; Hemais, Barbara Jane Wilcox (Advisor). Educational blog as a digital genre: A case study. Rio de Janeiro, 2007. p. 93 Master's Dissertation - Departamento de Letras, Pontifícia Universidade Católica do Rio de Janeiro.

The present study analyzes an educational blog maintained by a teacher in a preparatory course for an English language proficiency examination. The theoretical background of the study centers on the concept of genre as a recurring social action shared by a discourse community (Miller, 1994; Swales, 1990) and also on the notion of a system of genres (Bazerman, 2005). The system under study here emerged during the work of the teacher and the students towards the creation of the blog itself. The qualitative study consisted of, first, the tabulation of the genre system and then the investigation of genres that might be included in the blog, other than those common in classroom settings, considering that the blog is a multimedia digital genre. Through the analysis of a questionnaire sent to nine students participating in the blog, I also sought to check their perceptions as to the advantages of using the blog as far as their learning process was concerned. The data analysis showed that the genre system built during my observation consisted basically of a system that is very similar to one that might be observed in the traditional classroom environment. The results of the analysis of the questionnaires also showed that, for most of the students, blogging is seen as beneficial in terms of their learning although many students did not participate consistently in the activities proposed by the teacher. The pedagogical implications of this research indicate the need to reflect on the role of new digital genres concerning teachers' pedagogical practice and the possible contribution of these virtual genres in the teaching and learning process for foreign language nowadays.

\section{Keywords}

Emerging digital genres; Blog; Teaching/ learning process; Multimodality 


\section{SUMÁRIO}

$\begin{array}{ll}\text { Capítulo 1: Introdução } & 10\end{array}$

Capítulo 2: Fundamentação teórica 13

2.1. Gêneros discursivos 13

2.1.1. Bakhtin e os gêneros discursivos 13

2.1.2. Gênero como ação social 16

$\begin{array}{ll}\text { 2.1.3. Swales e os gêneros discursivos } & 18\end{array}$

2.1.4. A noção de gênero na linguística sistêmico-funcional 21

2.1.5. Gênero como ação social em Marcuschi 23

2.2. Gêneros discursivos em ambientes virtuais 24

2.3. Interação em gêneros digitais 30

2.4. O blog como gênero 33

2.5. Multimodalidade e design pedagógico 38

Capítulo 3: Metodologia de pesquisa 42

3.1. Corpus de pesquisa 44

3.2. Os participantes $\quad 44$

3.3. Os questionários $\quad 45$

Capítulo 4: Análise $\quad 49$

4.1. A comunidade discursiva dentro do blog 49

4.2. O sistema de gêneros 51

4.3. Analise dos questionários online 59

4.3.1. O professor bloguista $\quad 59$

$\begin{array}{ll}\text { 4.3.2. Os alunos do curso } & 60\end{array}$ 
Capítulo 5: Considerações finais

Referências bibliográficas

\section{ÍNDICE DE FIGURAS}

Figura 1: texto situado dentro de contextos extralinguísticos 23

Figura 2: visão global do CPE 50

Figura 3: postagem via aluno (M1) 52

Figura 4: exercício de completar lacunas 53

Figura 5: comentários de F2 e F5 seguidos de comentário do 53 professor

Figura 6: comentários de F5 e F2 a um vídeo 54

Figura 7: pergunta de F6 e resposta $\quad 55$

Figura 8: pergunta de F2 e resposta $\quad 56$

Figura 9: exercício de formação de palavras $\quad 87$

Figura 10: exercício de paráfrase $\quad 88$

Figura 11: exercício do tipo Cloze 89

Figura 12: exercício de prática escrita 90

Figura 13: cena de sitcom + exercício de prática escrita 90

Figura 14: dica de site ou link de interesse 91

Figura15: exercício de completar lacunas $\quad 91$

Figura 16: exercício de leitura 92

Figura 17: exercício de leitura ampliado 93

\section{ÍNDICE DE QUADROS}

Quadro 1: conceitos de comunidade discursiva (adaptado de Swales, 20 1990)

Quadro 2: Metafunções da linguagem (adaptado de Gouveia, 2009) 22

Quadro 3: elementos do contexto de situação 22

Quadro 4: parâmetros de análise dos gêneros virtuais 27 (adaptado de Marcuschi, 2004) 
Quadro 5: Modelo bidimensional de leitura (adaptado de Bezerra,

2007)

Quadro 6: Marcas de diferenciação fala/escrita de acordo com Chafe (adaptado de Souza, 2010:23-25)

Quadro 7: recursos estilísticos em e-mails (adaptado de Souza, 2010)

32

Quadro 8: estratégias de economia de notação gráfica (adaptado de Caiado, 2007)

Quadro 9: parâmetros para identificação do gênero blog (adaptado de Marcuschi, 2004)

Quadro 10: meios dentro do conceito de design pedagógico (adaptado de Jewitt, 2009)

Quadro 11: formulário investigativo para professor em branco $\quad 45$

Quadro 12: formulário investigativo para alunos em branco 47

Quadro 13: codificação dos membros 49

Quadro 14: sistema de gêneros do blog 51

Quadro 15: visão global do sistema de gêneros ao longo do período 57

Quadro 16: fatores diferenciais do blog do professor na pesquisa $\quad 60$

Quadro 17: profissão dos respondentes 61

Quadro 18: resumo das respostas (questões 4-7) 62

Quadro 19: visão geral das respostas ao questionário (alunos) 68

\section{ÍNDICE DE GRÁFICOS}

Gráfico 1: razões para obtenção do CPE 61

Gráfico 2: participação dos alunos no blog 63

Gráfico 3: contribuição à criação do blog 63

Gráfico 4: proveito do blog no processo ensino/aprendizagem 64

\section{ÍNDICE DE ANEXOS}

ANEXO 1: Quadro 20: respostas do professor bloguista 80

ANEXO 2: Quadro 21: respostas dos alunos 86

ANEXO 3: Exemplares de gêneros 87 